\title{
Short- and Long-term Progress of Recurrent Laryngeal Nerve Paralysis After Subtotal Esophagectomy
}

\author{
HIROKI SHIMIZU, ATSUSHI SHIOZAKI, HITOSHI FUJIWARA, HIROTAKA KONISHI, TOSHIYUKI KOSUGA, \\ SHUHEI KOMATSU, DAISUKE ICHIKAWA, KAZUMA OKAMOTO and EIGO OTSUJI
}

Division of Digestive Surgery, Department of Surgery, Kyoto Prefectural University of Medicine, Kyoto, Japan

\begin{abstract}
Aim: To clarify risk factors and long-term progress of postoperative recurrent laryngeal nerve paralysis $(P R N P)$ in patients with esophageal cancer. Patients and Methods: One hundred and twenty-five esophageal cancer patients, who underwent subtotal esophagetomy, including recurrent laryngeal nerve lymphadenectomy, were analyzed. A laryngoscopy was routinely performed to assess the motility of vocal cords. Results: PRNP was detected in 79 patients and $26(20.8 \%)$ patients required medical interventions (Grade II or more by the Clavien-Dindo classification; group II). Forty-one of 66 (62.1\%) patients recovered from PRNP with a median postoperative time of 135 days. The three-field lymphadenectomy and long operative time were the independent prognostic factors of group II. Conclusion: Radical operation caused PRNP with grade II or more. The long-term follow-up of vocal cords was necessary to detect patients with either transient or permanent PRNP.
\end{abstract}

Esophageal cancer is one of the most aggressive malignancies worldwide $(1,2)$ and curative surgical resection with systematic lymph node dissection remains a primary treatment to obtain better prognosis. However, esophagectomy for esophageal cancer has a high incidence of morbidity even with recent advances in surgical methods combined with perioperative management (3-5). In Japan, squamous cell carcinoma (SCC) is the predominant pathological type of esophageal cancer (6) and lymph nodes, along bilateral recurrent laryngeal nerves (RLNs), are involved in the regional lymph nodes and generally dissected against thoracic or cervical esophageal cancer (7). Thereby, recurrent laryngeal

Correspondence to: Atsushi Shiozaki, MD, Ph.D., Division of Digestive Surgery, Department of Surgery, Kyoto Prefectural University of Medicine, 465 Kajii-cho, Kawaramachihirokoji, Kamigyo-ku, Kyoto 602-8566, Japan. Tel: +81 752515527, Fax: +81 752515522, e-mail: shiozaki@koto.kpu-m.ac.jp

Key Words: Esophageal cancer, radical lymphadenectomy, laryngoscopy. nerve paralysis appears to be one of the major postoperative complications (8-10). As RLNs regulate motility of vocal cords, the injury of RLNs can cause hoarseness and disorders of swallowing and breathing and, sometimes, result in respiratory complications, such as aspiration pneumonia and airway obstruction. For this reason, the laryngoscopic assessment of the vocal cord motility has a significant role in the accurate diagnosis of postoperative recurrent laryngeal nerve paralysis (PRNP) and the management of postoperative complications related to PRNP (11) and is routinely performed for patients with esophagectomy in our Institute.

The incidence of PRNP, consecutive to esophagectomy, has been reported to range from $<1.0$ to $70 \%(8-10,12-17)$; however, the majority of these studies did not include patients who underwent lymphadenectomy along bilateral RLNs and assessment of vocal cord motility by laryngoscope. Moreover, some of these studies included patients who underwent transhiatal esophagectomy. In addition, only few studies reported the long-term follow-up of PRNP. Therefore, little is known about the predictors and the clinical outcomes of PRNP in patients with esophageal cancer after radical resection (10). The aim of this study was to clarify the incidence, risk factors and clinical course of PRNP following esophagectomy with lymphadenectomy along bilateral RLNs in esophageal SCC patients.

\section{Patients and Methods}

Patients. The medical records of 125 patients with esophageal SCC who underwent subtotal esophagectomy with systematic lymphadenectomy (curative R0 resection) in the Department of Surgery, Division of Digestive Surgery, Kyoto Prefectural University of Medicine, Japan, between 2008 and 2011 were reviewed. The following patients were excluded from this study (i) patients with preoperative recurrent laryngeal nerve paralysis, (ii) patients without undergoing lymphadenectomy along RLNs and (iii) patients who underwent planned tracheotomy pre- or intraoperatively. The present study conformed to the ethical guidelines of the World Medical Association Declaration of Helsinki Ethical Principles for Medical Research Involving Human Subjects. Written informed consent was obtained from all patients. 
Surgical treatment for primary tumor. All 125 patients underwent transthoracic esophagectomy via right thoracotomy and retrosternal construction using gastric tube with cervical anastomosis by handsewn technique. In our Institute, the patients with cervical and upper thoracic esophageal cancer generally underwent three-field (cervical, mediastinum, and abdomen) lymphadenectomy, while those with middle to lower thoracic and abdominal esophageal cancer underwent two-field (mediastinum, and abdomen) lymphadenectomy. The range of lymphadenectomy was determined according to Japanese classification of esophageal cancer (7). The enteric feeding tube was routinely placed.

Assessment of vocal cords. The motility of vocal cords was assessed using a laryngoscope by an otolaryngologist in our Institute before operation, at the extubation (usually postoperative day 1) and before starting meal (postoperative day 7). PRNP was defined when either complete or incomplete paralysis was detected at both laryngoscopy in twice after operation, but not before operation. The grade of recurrent laryngeal nerve paralysis was classified according to the Clavien-Dindo classification (18) and its supplementary criteria advocated by the Japan Clinical Oncology Group (JCOG) (19). In particular, grade I: clinical observation or diagnostic evaluation only (intervention not required); grade II: aspiration, medical management indicated; grade IIIa: severe aspiration, food intake almost impossible, medical intervention under local anesthesia indicated; grade IIIb: intervention under general anesthesia indicated (including tracheostomy under anesthesia); grade IVa: mechanical ventilation indicated; grade IVb: sepsis or multiple organ failure; grade V: death (19). Complications of grade II to V were defined only when the patients initially had PRNP. Then, the patients were divided into two groups; patients without PRNP or with PRNP of grade I (group I) and grade II or more (group II) who required any treatment intervention for PRNP. After hospital discharge, patients with PRNP were continuously followed once every three months by otolaryngologists at the outpatient clinic until their recovery. Vocal fold injection or medialization was not utilized.

Assessment of clinicopathological features. Various preoperative clinical and surgical features were analyzed. The recurrent laryngeal nerve lymph nodes with $10 \mathrm{~mm}$ or more in shorter diameter by multi-detector computed tomography (CT) scan were defined as metastatic lymph nodes. The preoperative treatment involved chemotherapy or chemoradiotherapy. The staging of tumors was classified according to the TNM classification for esophageal cancer, 7 th edition (20).

Statistical analysis. The Chi-square test and Fisher's exact test were used to evaluate the difference in proportion, while Student's $t$-test was used to evaluate the continuous variables. Multivariate logistic regression was used to identify risk factors associated with PRNP of grade II or more. All $p$-values less than 0.05 were considered significant.

\section{Results}

Of all 125 patients, 46 (36.8\%) had no PRNP, while 53 $(42.4 \%), 14(11.2 \%), 9(7.2 \%)$ and $3(2.4 \%)$ patients developed PRNP of grade I, II, IIIb and IVa, according to the Clavien-Dindo classification, respectively, and, therefore, the number of patients in group II was $26(20.8 \%)$.
The clinical characteristics, as well as the surgical and pathological outcomes of patients in each group are shown in Table I. The incidence of PRNP of grade II or more was significantly more related to cervical or upper esophageal located tumors $(p=0.007)$, three-field lymphadenectomy $(p=0.001)$ and long total operative time $(p=0.034)$. This incidence tends to be more frequent in patients with lower body mass index (BMI) $(p=0.053)$. However, there was no significant difference in other elements, including presence of preoperative treatment and lymph node metastasis along laryngeal recurrent nerve, between the two groups.

Multiple logistic regression analysis was performed based on range of lymphadenectomy, total operative time and BMI, where the $p$-value of univariate analysis was $<0.1$. Location of tumor was excluded considering its close correlation with range of lymphadenectomy. The analysis revealed that threefield lymphadenectomy and total operative time longer than 420 minutes were the independent risk factors associated with PRNP of grade II or more (Table II).

The short- and long-term clinical outcomes of PRNP in 79 patients are summarized in Table III. Twenty-five $(31.6 \%)$ patients developed bilateral vocal cord paralysis, while 47 and 7 patients of 54 patients with unilateral PRNP had left and right vocal cord paralysis, respectively. Bilateral vocal cord paralysis was significantly related to PRNP of grade II or more than unilateral vocal cord paralysis $(p<0.001)$. Two patients were excluded (1 with grade I and 1 with grade II) who died in hospital and 11 patients ( 7 with grade I and 4 with grade II or more) who had no follow-up assessment after hospital discharge; the remaining 66 patients were continuously followed by an otolaryngologist with a median follow-up time of 170 (range=26-1,758) days after operation. Thirty $(66.7 \%)$ of 45 patients with PRNP of grade I and 11 (52.4\%) of 21 patients with PRNP of grade II or more achieved a complete recovery from PRNP. The mean postoperative time for complete recovery from PRNP was 139 and 190 days in patients with grade I and II or more, respectively, and there was no statistical difference between the two groups $(p=0.466)$.

\section{Discussion}

This study revealed that the overall incidence of PRNP and PRNP with the Clavien-Dindo grade II or more after subtotal esophagectomy including lymphadenectomy along bilateral RLNs were $63.2 \%$ and $20.8 \%$ in patients with esophageal SCC, respectively. Furthermore, three-field lymphadenectomy and long operative time were selected as the independent risk factors associated with PRNP in need of treatment.

The frequency of PRNP in this study was quite high compared to other reports $(8-10,12-15,17)$. However, in those previous studies, the presence of PRNP was evaluated by clinical symptoms so that the incidence of asymptomatic PRNP, which could be detected only by a laryngoscope, was 
Table I. Clinicopathological characteristics of all patients.

\begin{tabular}{|c|c|c|c|c|}
\hline \multirow[b]{2}{*}{ Variable } & \multirow[b]{2}{*}{ Level } & \multicolumn{2}{|c|}{ Grade of PRNP } & \multirow[b]{2}{*}{$p$-Value } \\
\hline & & Group I ( $\mathrm{n}=99)$ & Group II (n=26) & \\
\hline \multirow[t]{2}{*}{ Gender } & Male & $82(82.8)$ & $22(84.6)$ & 1.000 \\
\hline & Female & $17(17.2)$ & $4(15.4)$ & \\
\hline Age, years & & $64.2 \pm 7.9$ & $65.4 \pm 9.3$ & 0.495 \\
\hline \multirow[t]{2}{*}{ Location of tumor } & $\mathrm{Ce} / \mathrm{Ut}$ & $16(16.1)$ & $11(42.3)$ & 0.007 \\
\hline & $\mathrm{Mt} / \mathrm{Lt}$ & $83(83.9)$ & $15(57.7)$ & \\
\hline Body mass index, $\mathrm{kg} / \mathrm{m}^{2}$ & & $21.2 \pm 3.3$ & $19.8 \pm 3.1$ & 0.053 \\
\hline \multirow[t]{2}{*}{ Serum albumin, $\mathrm{g} / \mathrm{dl}$} & $4.0 \leq$ & $62(62.6)$ & $14(53.8)$ & 0.500 \\
\hline & $<4.0$ & $37(37.4)$ & $12(46.2)$ & \\
\hline \multirow[t]{2}{*}{$\mathrm{HbA} 1 \mathrm{c}, \%$} & $5.8 \leq$ & $19(19.2)$ & $4(15.4)$ & 0.782 \\
\hline & $<5.8$ & $80(80.8)$ & $22(84.6)$ & \\
\hline \multirow[t]{2}{*}{ Metastasis of RLN LNs } & Negative & $73(73.7)$ & $17(65.4)$ & 0.463 \\
\hline & Positive & $26(26.3)$ & $9(34.6)$ & \\
\hline \multirow{2}{*}{ Preoperative treatment } & Negative & $30(30.3)$ & $6(23.1)$ & 0.628 \\
\hline & Positive & $69(69.7)$ & $20(76.9)$ & \\
\hline \multirow[t]{2}{*}{ Surgical approach } & Thoracotomy & $84(84.8)$ & $23(88.5)$ & 0.910 \\
\hline & Thoracoscopy & $15(15.2)$ & $3(11.5)$ & \\
\hline \multirow[t]{2}{*}{ Range of lymphadenectomy } & Two-field & $76(76.8)$ & $11(42.3)$ & 0.001 \\
\hline & Three-field & $23(23.2)$ & $15(57.7)$ & \\
\hline Amount of bleeding, $\mathrm{g}$ & & $504 \pm 520$ & $520 \pm 543$ & 0.888 \\
\hline Intrapleural operation time, min & & $112 \pm 50$ & $103 \pm 49$ & 0.400 \\
\hline Total operation time, $\min$ & & $413 \pm 68$ & $450 \pm 100$ & 0.034 \\
\hline \multirow[t]{2}{*}{ Metastasis of RLN LNs } & Negative & $79(79.8)$ & $18(69.2)$ & 0.292 \\
\hline & Positive & $20(20.2)$ & $8(30.8)$ & \\
\hline \multirow[t]{2}{*}{ Stage } & 0 -II & $51(51.5)$ & $15(57.7)$ & 0.661 \\
\hline & III-IV & $48(48.5)$ & $11(42.3)$ & \\
\hline
\end{tabular}

Values are $\mathrm{n}(\%)$ or mean \pm standard deviation unless otherwise indicated. PRNP, Postoperative recurrent laryngeal nerve paralysis; RLN LNs, recurrent laryngeal nerve lymph nodes; Ce, cervical esophagus; Ut, upper thoracic esophagus; Mt, middle thoracic esophagus; Lt, lower thoracic esophagus.

not included. The clinical impression of PRNP was often found to be incorrect (21). Pertl et al. (10) reported that a laryngoscopic evaluation was routinely performed for 84 esophageal cancer patients, with the incidence of unilateral PRNP being 50\% after esophagectomy followed by cervical anastomosis. In our study, the motility of vocal cords was visually assessed by a laryngoscope in all patients before and after surgery. Furthermore, the lymphadenectomy along bilateral RLNs was not performed or not described as the method of lymphadenectomy in most previous studies. In this work, all patients underwent a radical lymphadenectomy along bilateral RLNs, which could increase the risk of PRNP. Fujita et al. (16) reported that the rate of PRNP in thoracic esophageal squamous cell carcinoma (ESCC) patients after three-field lymphadenectomy was up to $70 \%$. Considering these two points, the incidence of PRNP in this study should be interpretable.

The Clavien-Dindo classification is widely used to present the results of postoperative complications (18). However, to the best of our knowledge, there has been no study reporting on the incidence of PRNP after esophagectomy using the
Table II. The multivariate association with PRNP.

\begin{tabular}{lccc}
\hline Variable & OR & $95 \%$ CI & $p$-Value \\
\hline $\begin{array}{l}\text { Body mass index, } \mathrm{kg} / \mathrm{m}^{2} \\
\quad<20 \text { versus } \leq 20\end{array}$ & 2.409 & $0.842-7.303$ & 0.102 \\
$\begin{array}{l}\text { Range of lymphadenectomy } \\
\quad \text { Three-field versus } \text { Two-field }\end{array}$ & 3.405 & $1.309-9.074$ & 0.012 \\
$\quad \begin{array}{l}\text { Total operation time, min } \\
\quad \leq 420 \text { versus }<420\end{array}$ & 3.737 & $1.230-12.544$ & 0.020 \\
\hline
\end{tabular}

PRNP, Postoperative recurrent laryngeal nerve paralysis; OR, odds ratio; CI, confidence interval.

Clavien-Dindo classification. This is mainly because the asymptomatic PRNP, which is grade I (42.4\% in this study), is hard to detect without laryngoscopy. Patients with PRNP of grade I may have a potential risk to develop into grade II or more. In our Institute, a routine perioperative swallowing rehabilitation was re-planned depending on the presence of PRNP and a videofluoroscopic examination of swallowing 
Table III. Long-term clinical outcomes of PRNP.

\begin{tabular}{|c|c|c|c|c|}
\hline \multirow[b]{2}{*}{ Variable } & \multirow[b]{2}{*}{ Level } & \multicolumn{2}{|c|}{ Grade of PRNP } & \multirow[b]{2}{*}{$p$-Value } \\
\hline & & Group I $(n=53)$ & Group II $(n=26)$ & \\
\hline \multirow[t]{2}{*}{ Pattern of paralysis } & Unilateral & $44(83.0)$ & $10(38.5)$ & \multirow[t]{2}{*}{$<0.001$} \\
\hline & Bilateral & $9(17.0)$ & $16(61.5)$ & \\
\hline \multirow[t]{2}{*}{ Persistent paralysis at hospital discharge } & Negative & $11(21.2)$ & $5(20.0)$ & \multirow[t]{2}{*}{1.000} \\
\hline & Positive & $41(78.8)$ & $20(80.0)$ & \\
\hline \multirow[t]{2}{*}{ Full recovery of PRNP } & Negative & $15(33.3)$ & $10(47.6)$ & \multirow[t]{3}{*}{0.289} \\
\hline & Positive & $30(66.7)$ & $11(52.4)$ & \\
\hline \multirow[t]{2}{*}{ Postoperative time for full recovery of PRNP, day } & & $\mathrm{n}=30$ & $\mathrm{n}=11$ & \\
\hline & & $139 \pm 65$ & $190 \pm 221$ & 0.466 \\
\hline
\end{tabular}

PRNP, Postoperative recurrent laryngeal nerve paralysis.

was considered to be added in order to prevent aspiration (data not shown).

In this study, multivariate analysis revealed that three-field lymphadenectomy and total operative time longer than 420 minutes were the independent risk factors associated with PRNP of grade II or more. In addition, previous studies also reported that three-field lymphadenectomy was significantly related to PRNP than two-field $(16,22)$. These results clearly suggested that surgical stress could be the major cause of PRNP. Some studies reported about the usefulness of intraoperative recurrent laryngeal nerve monitoring to prevent PRNP $(23,24)$. Recently, our group have established a new surgical technique, laparoscopic transhiatal esophagectomy without thoracoscopic procedure, to achieve less invasiveness (25-27) and reported a lower incidence of PRNP in patients with laparoscopic transhiatal esophagectomy (28). Further studies with a larger number of patients appear essential to emphasize this conclusion.

There have been few studies focusing on the long-term progress of PRNP $(10,17)$. Our study showed that $20.8 \%$ (16/77) of PRNP patients were healed before hospital discharge and $62.1 \%$ (41/66) of PRNP patients were found, by a laryngoscopic examination during the follow-up, to have fully recovered. In addition, the median postoperative time until full recovery was 135 days in these 41 patients. Baba et al. (17) reported that $41.2 \%$ of patients with PRNP on hospital discharge recovered within 1 year of esophagectomy and PRNP caused debilitation in quality of life. Considering these results, at least more than half a year after surgery should be necessary for follow-up, while proper education should be provided to each patient according to the motility of vocal cords.

In conclusion, PRNP with Clavien-Dindo grade II or more occurred in $20.8 \%$ after esophagetomy with recurrent nerve lymphadenectomy, with radical lymphadenectomy and longer operative time being risk factors. The long-term follow-up of vocal cords was important to detect patients with either transient or permanent PRNP.

\section{Acknowledgements}

The Authors thank colleagues from the Department of OtolaryngologyHead and Neck Surgery for their cooperation with laryngoscopic evaluation of vocal cord motility performed in this study.

\section{References}

1 Jemal A, Siegel R, Xu J and Ward E: Cancer statistics, 2010. CA: Cancer J Clin 60: 277-300, 2010.

2 Ferlay J, Soerjomataram I, Dikshit R, Eser S, Mathers C, Rebelo M, Parkin DM, Forman D and Bray F: Cancer incidence and mortality worldwide: Sources, methods and major patterns in GLOBOCAN 2012. Int J Cancer 136: E359-386, 2015.

3 Mantziari S, Hubner M, Demartines N and Schafer M: Impact of preoperative risk factors on morbidity after esophagectomy: is there room for improvement? World J Surg 38: 2882-2890, 2014.

4 Tekkis PP, McCulloch P, Poloniecki JD, Prytherch DR, Kessaris $\mathrm{N}$ and Steger AC: Risk-adjusted prediction of operative mortality in oesophagogastric surgery with O-POSSUM. Br J Surg 91: 288-295, 2004.

5 Lagarde SM, Reitsma JB, Maris AK, van Berge Henegouwen MI, Busch OR, Obertop H, Zwinderman AH and van Lanschot JJ: Preoperative prediction of the occurrence and severity of complications after esophagectomy for cancer with use of a nomogram. Ann Thorac Surg 85: 1938-1945, 2008.

6 Arnold M, Soerjomataram I, Ferlay J and Forman D: Global incidence of oesophageal cancer by histological subtype in 2012 . Gut 64: 381-387, 2015.

7 Japan Esophageal Society. Japanese classification of esophageal cancer. 11th ed. Tokyo: Kanehara, 2015.

8 Hulscher JB, van Sandick JW, Devriese PP, van Lanschot JJ and Obertop H: Vocal cord paralysis after subtotal oesophagectomy. Br J Surg 86: 1583-1587, 1999.

9 Gockel I, Kneist W, Keilmann A and Junginger T: Recurrent laryngeal nerve paralysis (RLNP) following esophagectomy for carcinoma. Eur J Surg Oncol 31: 277-281, 2005.

10 Pertl L, Zacherl J, Mancusi G, Gachter JN, Asari R, Schoppmann S, Bigenzahn W and Schneider-Stickler B: High risk of unilateral recurrent laryngeal nerve paralysis after esophagectomy using cervical anastomosis. Eur Arch Otorhinolaryngol 268: 1605-1610, 2011. 
11 Schneider B, Schickinger-Fischer B, Zumtobel M, Mancusi G, Bigenzahn W, Klepetko W and End A: Concept for diagnosis and therapy of unilateral recurrent laryngeal nerve paralysis following thoracic surgery. Thorac Cardiovasc Surg 51: 327-331, 2003.

12 Walther B, Johansson J, Johnsson F, Von Holstein CS and Zilling T: Cervical or thoracic anastomosis after esophageal resection and gastric tube reconstruction: A prospective randomized trial comparing sutured neck anastomosis with stapled intrathoracic anastomosis. Ann Surg 238: 803-812, 2003.

13 Orringer MB, Marshall B, Chang AC, Lee J, Pickens A and Lau CL: Two thousand transhiatal esophagectomies: Changing trends, lessons learned. Ann Surg 246: 363-372, 2007.

14 Yannopoulos P, Theodoridis P and Manes K: Esophagectomy without thoracotomy: 25 years of experience over 750 patients. Langenbecks Arch Surg 394: 611-616, 2009.

$15 \mathrm{Yu}$ Y, Wang Z, Liu XY, Zhu XF and Chen QF: Therapeutic efficacy comparison of two surgical procedures to treat middle thoracic esophageal carcinoma. World J Surg 34: 272-276, 2010.

16 Fujita H, Kakegawa T, Yamana H, Shima I, Toh Y, Tomita Y, Fujii T, Yamasaki K, Higaki K, Noake T, Ishibashi N and Mizutani K: Mortality and morbidity rates, postoperative course, quality of life, and prognosis after extended radical lymphadenectomy for esophageal cancer. Comparison of three-field lymphadenectomy with two-field lymphadenectomy. Ann Surg 222: 654-662, 1995.

17 Baba M, Natsugoe S, Shimada M, Nakano S, Noguchi Y, Kawachi $\mathrm{K}$, Kusano $\mathrm{C}$ and Aikou T: Does hoarseness of voice from recurrent nerve paralysis after esophagectomy for carcinoma influence patient quality of life? J Am Coll Surg 188: 231-236, 1999.

18 Dindo D, Demartines N and Clavien PA: Classification of surgical complications: a new proposal with evaluation in a cohort of 6336 patients and results of a survey. Ann Surg 240: 205-213, 2004.

19 Katayama H, Kurokawa Y, Nakamura K, Ito H, Kanemitsu Y, Masuda N, Tsubosa Y, Satoh T, Yokomizo A, Fukuda H and Sasako M: Extended Clavien-Dindo classification of surgical complications: Japan Clinical Oncology Group postoperative complications criteria. Surg Today 46(6): 668-685, 2016.

20 Sobin LH WC, Gospodarowicz M (eds): TNM classification of malignant tumours (UICC) 7th ed: New York: Wiley-Blackwell, 2009.

21 Johnson PR, Kanegoanker GS and Bates T: Indirect laryngoscopic evaluation of vocal cord function in patients undergoing transhiatal esophagectomy. J Am Coll Surg 178: 605-608, 1994.
22 Ma GW, Situ DR, Ma QL, Long H, Zhang LJ, Lin P and Rong TH: Three-field vs two-field lymph node dissection for esophageal cancer: a meta-analysis. World J Gastroenterol 20: 18022-18030, 2014.

23 Gelpke H, Grieder F, Decurtins M and Cadosch D: Recurrent laryngeal nerve monitoring during esophagectomy and mediastinal lymph node dissection. World J Surg 34: 2379-2382, 2010.

24 Zhong D, Zhou Y, Li Y, Wang Y, Zhou W, Cheng Q, Chen L, Zhao J, Li X and Yan X: Intraoperative recurrent laryngeal nerve monitoring: A useful method for patients with esophageal cancer. Dis Esophagus 27: 444-451, 2014.

25 Shiozaki A, Fujiwara H, Konishi H, Morimura R, Komatsu S, Murayama Y, Kuriu Y, Ikoma H, Kubota T, Nakanishi M, Ichikawa D, Okamoto K, Sakakura C and Otsuji E: Middle and lower esophagectomy preceded by hand-assisted laparoscopic transhiatal approach for distal esophageal cancer. Mol Clin Oncol 2: 31-37, 2014.

26 Shiozaki A, Fujiwara H, Murayama Y, Komatsu S, Kuriu Y, Ikoma H, Nakanishi M, Ichikawa D, Okamoto K, Ochiai T, Kokuba $\mathrm{Y}$ and Otsuji E: Perioperative outcomes of esophagectomy preceded by the laparoscopic transhiatal approach for esophageal cancer. Dis Esophagus 27: 470-478, 2014.

27 Fujiwara H, Shiozaki A, Konishi H, Kosuga T, Komatsu S, Ichikawa D, Okamoto K and Otsuji E: Single-port mediastinoscopic lymphadenectomy along the left recurrent laryngeal nerve. Ann Thorac Surg 100: 1115-1117, 2015.

28 Fujiwara H, Shiozaki A, Konishi H, Komatsu S, Kubota T, Ichikawa D, Okamoto K, Morimura R, Murayama Y, Kuriu Y, Ikoma H, Nakanishi M, Sakakura C and Otsuji E: Hand-assisted laparoscopic transhiatal esophagectomy with a systematic procedure for en bloc infracarinal lymph node dissection. Dis Esophagus 29: 131-138, 2016.
Received February 2, 2017

Revised March 13, 2017

Accepted March 14, 2017 